\title{
US data on industry payments to doctors
}

$\mathrm{T}$ he US government's release of data on billions of dollars in industry payments to physicians and teaching hospitals is attracting envy from Canadian advocates for medical transparency and accountability.

The data, which were released Sept. 30 by the Centers for Medicare $\&$ Medicaid Services (CMS), a branch of the US Department of Health and Human Services that manages care for more than 100 million Americans, describe 4.4 million payments totalling $\$ 3.5$ billion. The payments were from commercial sources for "consulting fees, research grants, travel reimbursements, and other gifts" made to 546000 US physicians and 1360 teaching hospitals during the last five months of 2013.

Early analyses of the data reveal that some drug-makers spend lavishly on doctors, especially doctors from a small subset identified as "thoughtleaders" who communicate with their peers most energetically in return for compensation in cash or luxury travel and other in-kind payments.

"This is an opportunity for the public to learn about the relationships among health care providers, and pharmaceutical and device companies," CMS Administrator Marilyn Tavenner said in a statement accompanying the release of the data on CMS's "Open Payments" website. The release was mandated under the "Sunshine" section of the US government's 2010 Patient Protection and Affordable Care Act.

Not all financial relationships between clinicians should be viewed as improper, the CMS cautions. In a statement emphasizing "the importance of discouraging inappropriate relationships without harming beneficial ones" the agency underlined that many payments support research and other medically important activities.

But with the pharmaceutical industry alone spending about $\$ 30$ billion per year promoting products, and with $90 \%$ of that money directed to physicians and

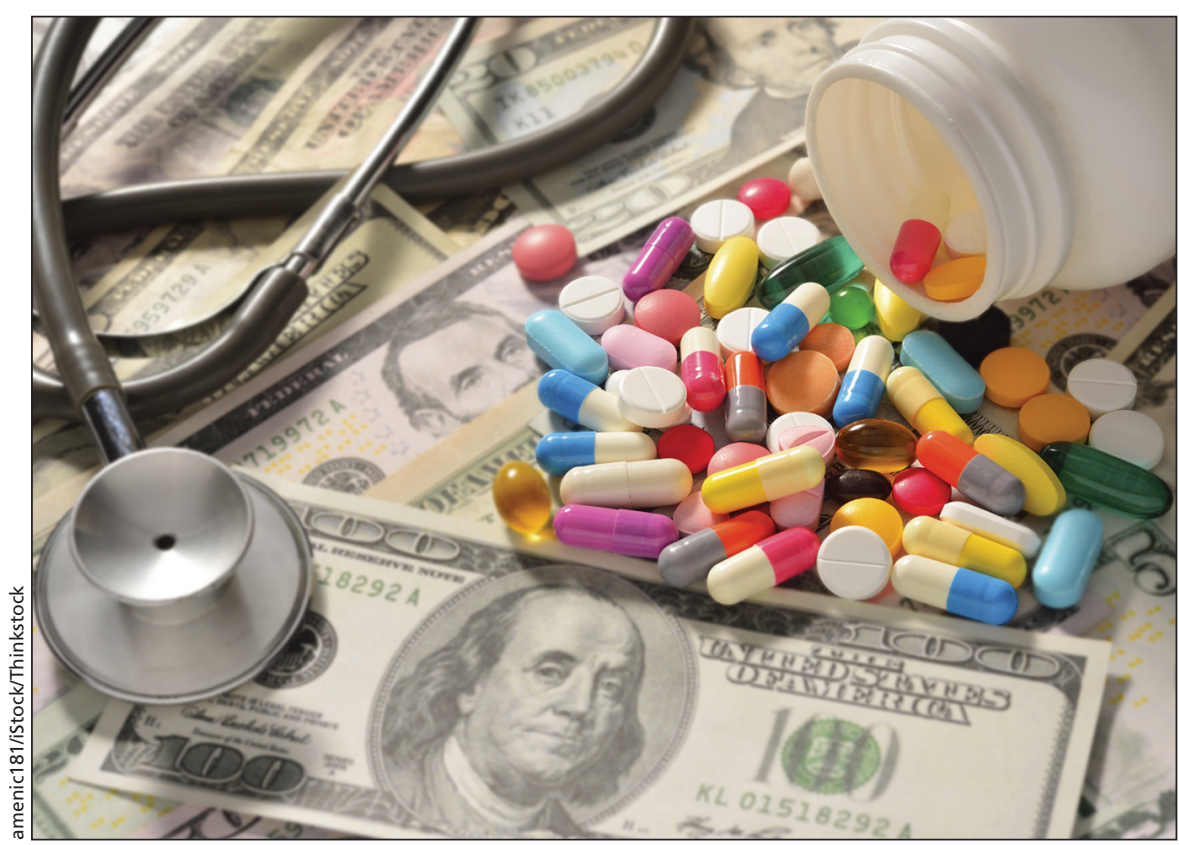

New data from the US describe 4.4 million payments to physicians totalling $\$ 3.5$ billion.

other prescribers, the scale of inappropriate relationships aimed at distorting evidence-based clinical judgments for commercial gain is potentially significant, says Neil Kirschner, senior associate for Health Policy and Regulatory Affairs, American College of Physicians.

"Plenty of studies have shown that marketing relationships between physicians and health care companies can introduce conflicts of interest that influence prescribing, research, education, use, and ultimately patient outcomes," says Kirschner. "And there is substantial evidence that this is often in ways that favor the company's interests."

The primary beneficiaries of the CMS disclosure will be patients, Kirschner believes. "The public availability of this data will increase patients' trust in doctors," he says. "The evidence suggests even little things like meals can have an effect on prescribing and that there will likely be a reduction now in things you would want reduced, like free trips for doctors paid for by industry."

These observations, Kirschner notes, are rooted in evidence after the
State of Massachusetts began publishing state-wide data in 2004 similar to what CMS has released (Arch Intern Med 2010;170:1820-6).

Dr. Leana Wen, founder of Who's My Doctor?, an advocacy group calling for full physician disclosure of all commercial relationships, agrees with Kirschner's view that the CMS data dump will yield salutary results for patients.

These latest data are a "very good start," but Wen would like to see far more financial data made available, including information about how physicians are paid. "It can make a huge difference to the care they receive if payment is by volume of procedures delivered." The group is also calling for physician disclosure about their political affiliations and "philosophy of practice" concerning issues such as contraception, abortion, early breast cancer screenings and vaccination.

Kirschner and Wen both mix their praise for the CMS with criticism of the quality and scope of the data released so far. The information is for a partial year only, and about one-third of the records 
were withheld due to concerns about accuracy voiced by the American Medical Association and other groups. CMS's decision to exempt payments within continuing medical education programs also attracted heat.

Despite the shortfalls, Canadian lawmakers should follow the US lead, says Dr. Andrew Boozary, cofounder of Open Pharma, a Toronto-based group that advocates for greater medical trans- parency. "A province like Ontario could take up this charge. There's no doubt that patients benefit from financial disclosure."

Boozary notes that conflict-of-interest disclosures are now the norm in medical research and publishing. "Patients clearly deserve the same."

Emily Nicholas, spokesperson for Patients Canada, another group that advocates for medical transparency, agrees. "It seems contradictory for a health system or government to promote patient engagement, patientpartnership, self-management and shared decision making and yet withhold certain information that they believe patients don't need, can't handle, or will over-react to." — Paul Webster, Toronto, Ont.

CMAJ 2014. DOI:10.1503/cmaj.109-4926 